\title{
HIDRÓLISE ENZIMÁTICA DE ÓLEO DE SOJA EM REATOR DE LEITO FIXO UTILIZANDO A LIPASE LIPOZYME TL IM
}

\author{
E. RAIZER ${ }^{1}$, T. O. REINEHR ${ }^{1}$, G. P. de SÁ Jr. ${ }^{1}$, J. A. AWADALLAK ${ }^{1}$, C. R. BRITO Jr. ${ }^{1}$, C. \\ SILVA $^{2}$ e E. A. SILVA ${ }^{1}$ \\ ${ }^{1}$ Universidade Estadual do Oeste do Paraná, Departamento de Engenharia Química \\ ${ }^{2}$ Universidade Estadual de Maringá, Departamento de Engenharia Química \\ E-mail para contato: eduardoeq@gmail.com
}

\begin{abstract}
RESUMO - Os ácidos graxos possuem diversas aplicações industriais e servem de substratos para inúmeros produtos, principalmente dentro da indústria alimentícia, onde um alto grau de pureza se faz necessário e é dificilmente alcançado quando sua produção envolve catalisadores químicos. Além disso, a reação de hidrólise geralmente necessita de altas temperaturas e pressões para ocorrer, o que pode ser contornado com o uso de enzimas (lipases) como catalisador, as quais utilizam condições reacionais mais brandas. Dentro deste contexto, este projeto teve como principal objetivo avaliar o processo de hidrólise enzimática do óleo de soja em um reator de leito fixo tubular usando como catalisador a enzima Lipozyme TL IM e avaliar os efeitos da razão mássica água/substrato e da temperatura no rendimento da reação por meio de um planejamento experimental. As reações de hidrólise foram realizadas a temperaturas de 20,25 e $30^{\circ} \mathrm{C}$, em concentrações de 4,8 e $12 \%$ de água em relação à massa total e tempo de residência de uma hora. Nas melhores condições, foi produzido um óleo com acidez final de $24,46 \%$.
\end{abstract}

\section{INTRODUÇÃO}

As atuais tendências nutricionais têm tornado a dieta cotidiana rica em óleos e gorduras, que aliada à falta de atividades físicas regulares, está associada a um aumento no índice de obesidade da população, aumentando os riscos de doenças cardiovasculares, diabetes e hipertensão (Francischi et al., 2000). Entretanto, os óleos e gorduras possuem um papel fundamental no funcionamento do corpo humano, fornecendo energia, atuando no transporte de vitaminas lipossolúveis e também como fontes de ácidos graxos essenciais (Castro et al., 2004). Não podendo, dessa forma, ser totalmente dispensados da alimentação diária (Yang et al., 2004).

Um crescente interesse por tecnologias de modificação de óleos e gorduras surgiu nos últimos anos, impulsionado pela importância dessas substâncias enquanto matérias-primas para as indústrias químicas, farmacêuticas e alimentícias (Castro et al., 2004).

O principal componente dos óleos e gorduras é o Triacilglicerol (TAG), e por meio de sua hidrólise parcial, obtém-se o diacilglicerol (DAG) e os ácidos graxos. Segundo Awadallak (2012), apesar de atingir conversões menores, a hidrólise é uma reação direta que utiliza como substratos óleos e gorduras naturais. A produção de ácidos graxos por esse processo é um componente muito 
importante na exploração econômica dessas fontes renováveis. Um significante número de produtos de alto valor agregado como revestimentos, colas, óleos lubrificantes, xampus e outros produtos de cuidados pessoais requer o uso de ácidos graxos em sua fabricação (Murty, et al., 2002).

A utilização de catalisadores na hidrólise é muito comum, pondendo ser conduzida através de catalisadores químicos ou enzimáticos. $\mathrm{O}$ uso de processos enzimáticos apresenta certas vantagens, como a atuação em condições operacionais brandas de temperatura, $\mathrm{pH}$ e pressão, velocidades de reação bastante superiores àquelas obtidas em presença de catalisadores químicos convencionais (Mendes et al., 2011), assim como uma maior especificidade, gerando menos produtos indesejáveis e resultando também em uma maior facilidade de separação do meio. No entanto, de forma geral, as enzimas possuem um alto custo de aquisição, reduzindo assim sua utilização, quando comparadas aos catalisadores químicos.

Nesse contexto, o objetivo deste trabalho foi a produção de ácidos graxos livres com alto grau de conversão, através da hidrólise do óleo de soja em leito fixo com a utilização da enzima Lipozyme TL IM.

\section{MATERIAIS E MÉTODOS}

O substrato da reação de hidrólise utilizado neste trabalho foi o óleo de soja. A lipase comercial Lipozyme TL IM, utilizada como catalisador foi cedida por LFN Latino América. Uma solução de fenolftaleína $\left(\right.$ Synth $\left.{ }^{\circledR}\right)$ foi utilizada como indicador para medidas de acidez do óleo. Etanol absoluto $\left(\right.$ Chemco $\left.{ }^{\circledR}\right)$, Éter etílico $\left(\right.$ Nuclear $\left.{ }^{\circledR}\right)$ e $\mathrm{NaOH}\left(\right.$ Synth $\left.{ }^{\circledR}\right)$ foram utilizados na determinação da acidez.

\subsection{Delineamento experimental}

A influência da razão água/substrato e da temperatura na formação de ácidos graxos, foi verificada por um delineamento central composto rotacional com duas variáveis. Como variável resposta foi considerado o grau de acidez após $1 \mathrm{~h}$ de reação. A análise dos dados foi efetuada por meio do programa Statistica ${ }^{\circledR}$ (versão 10). As hidrólises foram realizadas em um reator encamisado contendo $20 \mathrm{~mL}$ de emulsão numa proporção água:substrato, por um período de $1 \mathrm{~h}$ com temperaturas fixas e agitação magnética $(350 \mathrm{rpm})$.

\subsection{Preparação das amostras}

Os experimentos foram preparados dentro de um reator encamisado, em concentrações de 4, 8 e $12 \%$ de água deionizada em relação à massa total de substrato (água + óleo), fixada em 20 g. Após a conexão do reator encamisado ao sistema, as reações foram realizadas a temperaturas de 20,25 e $30^{\circ} \mathrm{C}$. 


\subsection{Reações de hidrólise}

As reações de hidrólise enzimática do óleo de soja foram conduzidas em um sistema contínuo composto por um reator encamisado conectado a um reator de leito fixo tubular encamisado, preenchido com 1,4 g de enzima e completado com pérolas de vidro, conforme mostra a Figura 1.

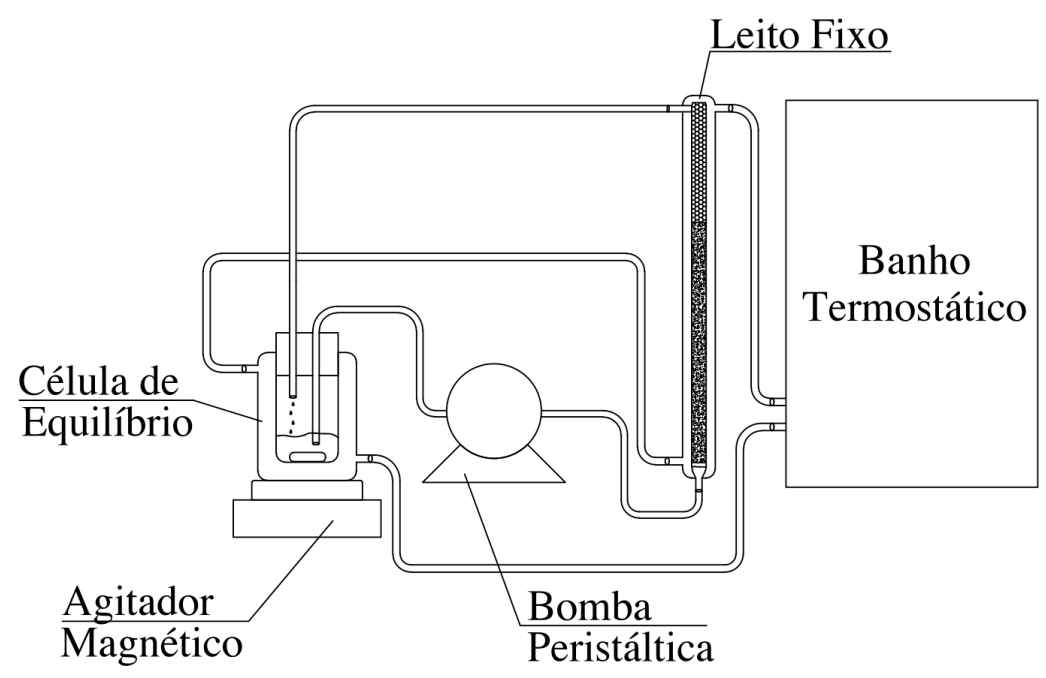

Figura 1 - Módulo de reação de hidrólise.

A mistura foi transportada pelo sistema através de uma bomba peristáltica Cole-Parmer, e a temperatura foi controlada com auxílio de um banho termostático Marconi.

Após a reação, as amostras foram aquecidas durante 24 horas a uma temperatura de $105^{\circ} \mathrm{C}$ para assegurar a evaporação da água, e em seguida o teste de acidez foi realizado.

\subsection{Quantificação da acidez}

A quantidade de ácidos graxos livres presentes no óleo foi determinada por titulação com solução de $\mathrm{NaOH}$. Uma solução de $50 \mathrm{~mL}$ de etanol absoluto e éter etílico em proporção 1:1 com cerca de $1 \mathrm{~g}$ de óleo e duas gotas de solução de fenolftaleína foi titulada com uma solução de $\mathrm{NaOH}$ $0,05 \mathrm{M}$ sob agitação vigorosa até a mudança de coloração (mudança súbita de uma coloração branca para rosa). A acidez do óleo foi calculada de acordo com a seguinte relação:

$$
\operatorname{Acidez}(m \%)=100 \frac{\operatorname{Vol} M_{N a O H} P M_{A G L}}{p a}
$$




\section{RESULTADOS E DISCUSSÃO}

O estudo das condições controláveis se deu através da metodologia de superfície de resposta, utilizando um planejamento experimental do tipo delineamento central composto rotacional (DCCR). Para tempos de reação fixos de duas horas, variou-se a razão água/substrato e a temperatura.

A Tabela 1 representa as variáveis e níveis para o planejamento experimental.

Tabela 1 - Variáveis e níveis para o DCCR

\begin{tabular}{rccccc}
\hline & $-\sqrt{ } \mathbf{2}$ & $\mathbf{- 1}$ & $\mathbf{0}$ & $\mathbf{1}$ & $\sqrt{\mathbf{2}}$ \\
\hline \hline Razão água/substrato (\%) & 2,34 & 4 & 8 & 12 & 13,66 \\
Temperatura ( $\left.{ }^{\mathbf{0}} \mathbf{C}\right)$ & 17,93 & 20 & 25 & 30 & 32,07 \\
\hline
\end{tabular}

O projeto do experimento consistiu em um planejamento do tipo delineamento central composto rotacional para duas variáveis, com quatro repetições no ponto central para a avaliação do erro e dois pontos axiais no eixo de cada variável, resultando em quinze experimentos. A Tabela 2 apresenta a estimativa dos efeitos em conjunto com o gráfico de Pareto (Figura 2).

Tabela 2 - Estimativa dos efeitos

\begin{tabular}{lrrrr}
\hline \multicolumn{1}{c}{ Variável } & \multicolumn{1}{c}{ Efeito } & Erro padrão & p-valor & Coeficiente \\
\hline \hline Intercepto & 16,5642 & 0,6321 & 0,000000 & 16,5642 \\
(1) Temperatura (L) & 0,4230 & 0,7879 & 0,604400 & 0,2115 \\
Temperatura (Q) & $-3,1520$ & 0,9818 & 0,010653 & $-1,5760$ \\
(2) Razão Água/Substrato (L) & 12,1855 & 1,1100 & 0,000002 & 6,0928 \\
Razão Água/Substrato (Q) & 1,1072 & 1,9659 & 0,587068 & 0,5536 \\
Interação (1) com (2) & $-0,3977$ & 1,7447 & $-0,227970$ & 0,8248 \\
\hline
\end{tabular}

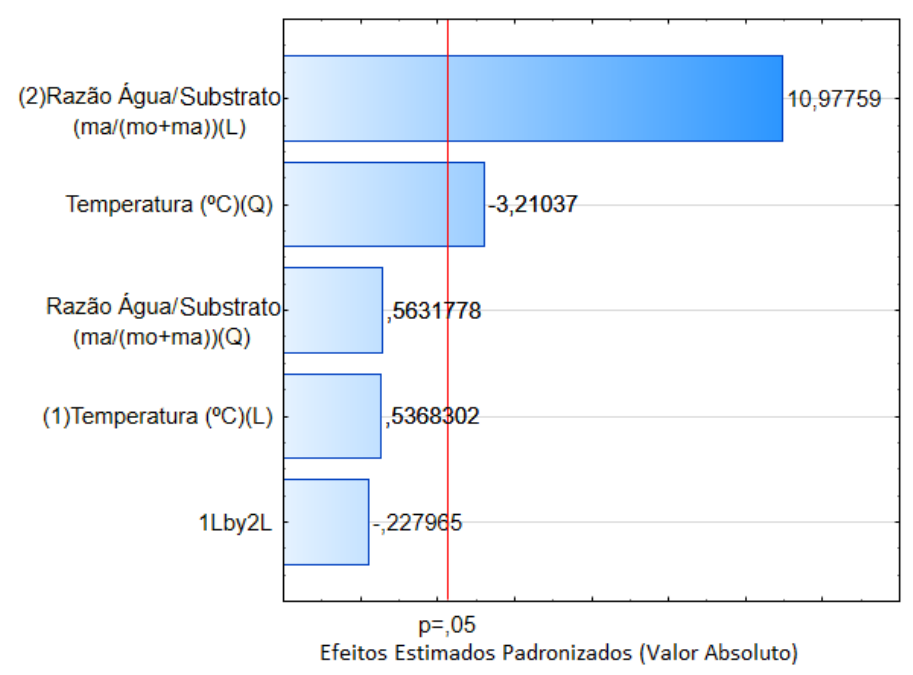

Figura 2 - Gráfico de Pareto. 
A variável Razão água/substrato (linear) e a variável Temperatura (quadrática) apresentaram, para um nível de significância de $5 \%$, efeitos significativos sobre a conversão em AGL. A variável Temperatura (quadrática) indica a existência de um ponto máximo de conversão dentro do intervalo estudado, enquanto a falta de curvatura presente no ajuste quadrático do intervalo testado para a Razão água/substrato indica que tanto esse intervalo quanto suas proximidades não contém um ponto ótimo.

A Tabela 3 representa a matriz de dados do DCCR para as variáveis estudadas e as respostas obtidas em termos de porcentagem de acidez experimental e predita.

Tabela 3 - Condições experimentais e resultados

\begin{tabular}{ccccc}
\hline Amostra & $\begin{array}{c}\text { Razão Água/Substrato } \\
(\mathrm{ma} /(\mathrm{mo}+\mathrm{ma}))\end{array}$ & $\begin{array}{c}\text { Temperatura } \\
\left({ }^{\circ} \mathrm{C}\right)\end{array}$ & $\begin{array}{c}\text { Acidez } \\
\text { Experimental } \\
(\%)\end{array}$ & $\begin{array}{c}\text { Acidez } \\
\text { Predita } \\
(\%)\end{array}$ \\
\hline \hline 1 & $2,34 \%$ & 25,00 & 9,01 & 10,91 \\
2 & $4,00 \%$ & 20,00 & 10,79 & 10,49 \\
3 & $4,00 \%$ & 30,00 & 12,23 & 11,23 \\
4 & $4,00 \%$ & 25,00 & 14,44 & 12,44 \\
5 & $8,00 \%$ & 25,00 & 16,30 & 16,52 \\
6 & $8,00 \%$ & 25,00 & 16,02 & 16,52 \\
7 & $8,00 \%$ & 32,10 & 13,82 & 13,66 \\
8 & $8,00 \%$ & 30,00 & 14,48 & 15,17 \\
9 & $8,00 \%$ & 20,00 & 14,65 & 14,72 \\
10 & $8,00 \%$ & 25,00 & 16,42 & 16,52 \\
11 & $8,00 \%$ & 17,90 & 13,96 & 13,03 \\
12 & $12,00 \%$ & 30,00 & 18,95 & 19,68 \\
13 & $12,00 \%$ & 20,00 & 18,16 & 19,52 \\
14 & $12,00 \%$ & 25,00 & 21,76 & 21,18 \\
15 & $13,66 \%$ & 25,00 & 24,46 & 23,28 \\
\hline
\end{tabular}

Embora o ponto máximo da reação ainda não tenha sido determinado devido ao baixo intervalo de testes realizados para a razão água/substrato, bons resultados foram alcançados. As respostas preditas foram obtidas pelo ajuste de um modelo quadrático feito pelo software Statistica ${ }^{\circledR}$. A acidez mostrou-se dependente tanto da razão água/substrato quanto da temperatura, segundo o gráfico de Pareto (Figura 2). Essa relação é descrita através da Equação 2:

$$
\operatorname{Acidez}(m \%)=-33,00+3,25 T-0,06 T^{2}+98,53 R+178,78 R^{2}-0,71 R T
$$

$\mathrm{O}$ coeficiente de correlação ao quadrado $\mathrm{R}^{2}$ é comumente utilizado como parâmetro de avaliação para a eficiência de modelo modelos matemáticos. Quanto mais próximo da unidade, mais fiel tende a ser a correlação aos dados experimentais. Neste caso o valor de $\mathrm{R}^{2}$ foi de em 0,371 , indicando um ajuste satisfatório, porém passível de melhora.

Através da regressão foi possível traçar o gráfico de superfície para a acidez em função das 
variáveis de entrada. A Figura 3 mostra a superfície para a acidez final em função da razão água/substrato e da massa de temperatura.

Através do gráfico é possível perceber que a razão água/substrato está diretamente relacionada com o desempenho da reação e que o aumento da temperatura está provavelmente associado à desativação da enzima.

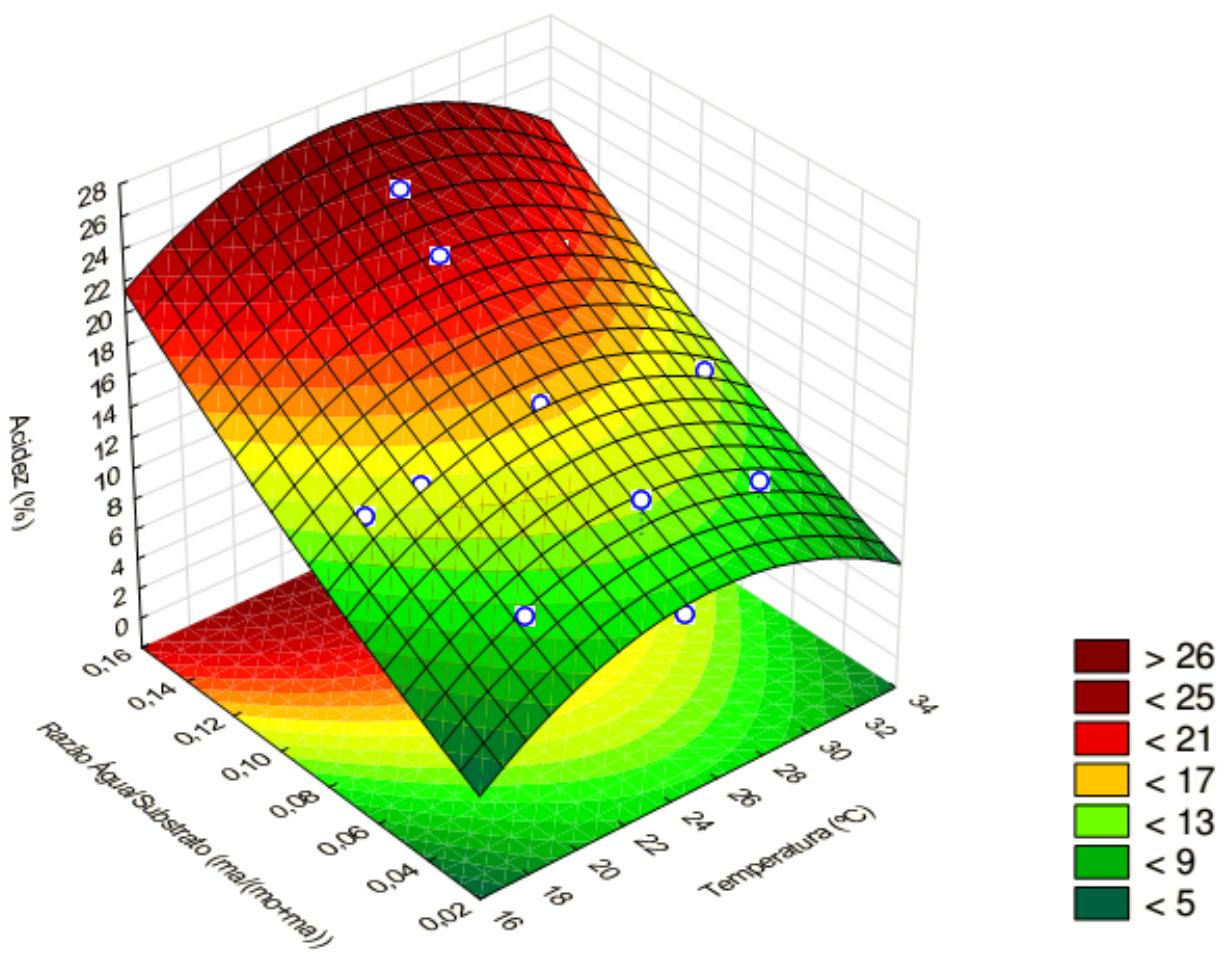

Figura 3 - Acidez em função da temperatura e da razão água/substrato.

As análises de variância e de resíduos, obtidas através do software Statistica ${ }^{\circledR}$ estão descritas na Tabela 3 e na Figura 4.

Tabela 3 - Análise de variância

\begin{tabular}{cccccc}
\hline $\begin{array}{c}\text { Fonte de } \\
\text { variação }\end{array}$ & $\begin{array}{c}\text { Soma dos } \\
\text { Quadrados }\end{array}$ & $\begin{array}{c}\text { Graus de } \\
\text { Liberdade }\end{array}$ & $\begin{array}{c}\text { Quadrado } \\
\text { Médio }\end{array}$ & $\mathrm{F}_{\text {calc }}$ & $\mathrm{F}_{\text {tab }}$ \\
\hline \hline Regressão & 208,722 & 5 & 41,744 & 26,816 & 3,388 \\
Resíduos & 14,01 & 9 & 1,557 & & \\
Total & 222,732 & 14 & & & \\
\hline
\end{tabular}




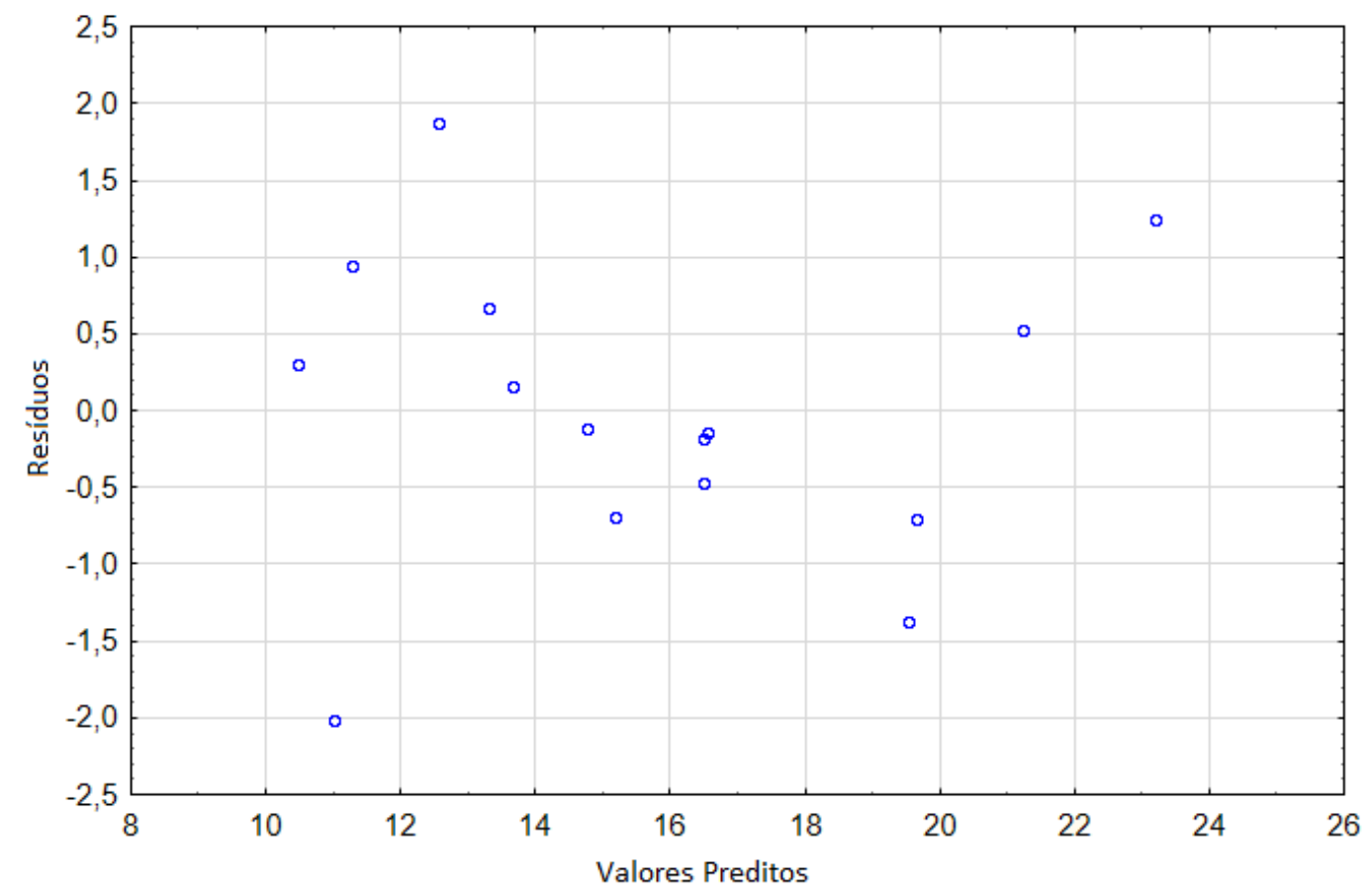

Figura 4 - Resíduos.

\section{CONCLUSÕES}

Para um intervalo de confiança de $95 \%$, as variáveis Temperatura (quadrática) e Razão água/substrato (linear) apresentaram efeitos significativos sobre a conversão em AGL. A presença de um ponto máximo de conversão dentro do intervalo de temperatura estudado foi encontrada, enquanto o intervalo testado para a razão água/substrato evidenciou a falta de curvatura no ajuste quadrático, mostrando que tanto esse intervalo quanto suas proximidades não possuem ponto ótimo. $\mathrm{O}$ coeficiente de correlação obtido foi de $\mathrm{R}^{2}=0,9371$. Esse resultado em conjunto com os valores relativamente baixos dos resíduos, bem como sua distribuição aleatória em torno de zero e um valor de $\mathrm{F}_{\text {calc }}$ muito maior que $\mathrm{F}_{\text {tab }}$ são fortes indicações de que o ajuste quadrático é satisfatório e não tendencioso. No entanto ainda são necessários mais testes em outras faixas de razão água/substrato para determinar com alto grau de confiança qual o ponto ótimo da reação de hidrólise do óleo de soja em leito fixo.

\section{NOMENCLATURA}

ma: $\quad$ Massa de água

(g)

$M_{\mathrm{NaOH}}$ : Molaridade das solução de $\mathrm{NaOH}$

$(\mathrm{mol} / \mathrm{L})$ 
mo: $\quad$ Massa de óleo

(g)

pa: $\quad$ Massa da amostra de óleo para titulação

(g)

$P M_{A G L}$ : Peso molecular médio dos ácidos graxos presentes no óleo $(\mathrm{g} / \mathrm{mol})$
R: $\quad$ Razão água/substrato
$\left(\mathrm{M}_{\text {água }} / \mathrm{M}_{\text {água }}+\mathrm{M}_{\text {óleo }}\right)$
T: $\quad$ Temperatura
$\left({ }^{\circ} \mathrm{C}\right)$

Vol: Volume de solução de $\mathrm{NaOH}$ gasto na titulação da solução (L)

\section{REFERENCIAS}

AWADALLAK, J.A. Uso do ultrassom na hidrólise enzimática do óleo de palma: síntese de diacilglicerol. Dissertação de mestrado em Engenharia Química, Universidade Estadual do Oeste do Paraná, Toledo, 2012.

CASTRO, H. F.; MENDES A.A.; SANTOS, J.C.; AGUIAR, C.L. Modificações de óleos e gorduras por biotransformação. Quím. Nova, v. 27, p. 146-156, 2004.

FRANCISCHI, R.P.P.; PEREIRA, L.O.; FREITAS, C.S.; KLOPFER, M.; SANTOS, R.C.; VIEIRA, P.; LANCHA JUNIOR, A.H. Obesity: updated information about its etiology, morbidity and treatment. Rev. Nutr., v. 13, p. 17-28, 2000.

MENDES, A. A.; OLIVEIRA, P. C.; CASTRO, H. F.; GIORDANO, R. L. C. Aplicação de quitosana como suporte para a imobilização de enzimas de interesse industrial. Quím. Nova, v. 34, p. 831-841, 2011.

MURTY, R. V.; BHAT, J.; MUNISWARAN P. K. A. Hydrolysis of Oils by Using Immobilized Lipase Enzyme: A Review. Biotechnol. Bioproccess Eng. v. 7, p. 57-66, 2002.

YANG, T.; ZHANG, H.; MU, H.; SINCLAIR, A.J.; XU, X. Diacylglycerols from butterfat: Production by glycerolysis and short path distillation and analysis of physical properties. Journal of the American Oil Chemists' Society, v. 81, p. 979-987, 2004. 